\title{
CARACTERÍSTICAS E INFLUÊNCIAS DA DIMENSÃO ECONÔMICA DA GASTRONOMIA CRIATIVA DO RIBEIRÃO DA ILHA, EM FLORIANÓPOLIS/SC, BRASIL, PARA $O$ TURISMO CRIATIVO LOCAL: ESTUDO DE CASO DE UMA CIDADE CRIATIVA UNESCO DA GASTRONOMIA
}

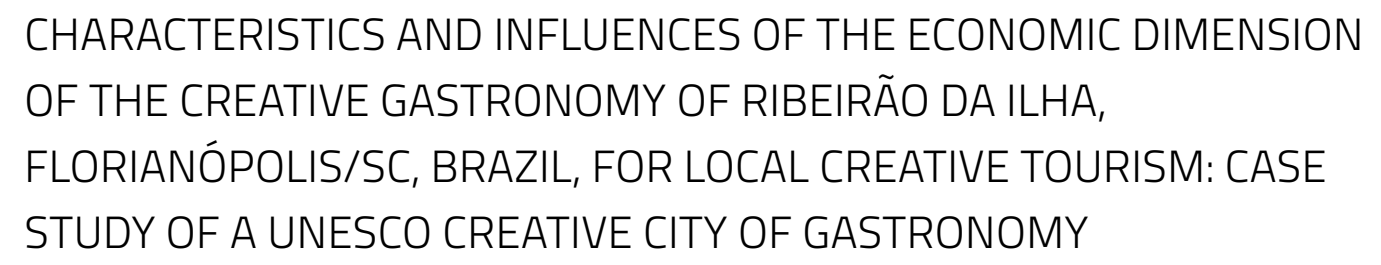

CHARACTERISTICS AND INFLUENCES OF THE ECONOMIC DIMENSION

OF THE CREATIVE GASTRONOMY OF RIBEIRÃO DA ILHA,

FLORIANÓPOLIS/SC, BRAZIL, FOR LOCAL CREATIVE TOURISM: CASE

STUDY OF A UNESCO CREATIVE CITY OF GASTRONOMY

\section{Luiz Daniel Muniz Junqueira}

Professor das áreas de Turismo, Hospitalidade e Lazer do IFB (Brasília/Brasil).

Doutor em Turismo e Hotelaria pela UNIVALI (Florianópolis/Brasil).

E-mail: luiz.junqueira@ifb.edu.br.

\section{Francisco Antônio dos Anjos}

Professor do Doutorado e Mestrado em Turismo e

Hotelaria da UNIVALI (Balneário Camboriú/Brasil).

Doutor em Engenharia de Produção pela Universidade

Federal de Santa Catarina (Florianópolis/Brasil).

E-mail: anjos@univali.br. 


\section{RESUMO}

O turismo e a gastronomia são atividades dinamizadoras da economia de uma localidade. Neste contexto, a pesquisa teve como objetivo analisar as características da dimensão econômica da cadeia produtiva da gastronomia criativa de Florianópolis e a sua influência no desenvolvimento do turismo local. Como metodologia adotou-se a abordagem qualitativa realizando 13 entrevistas com atores envolvidos na cadeia produtiva da gastronomia local, associando um levantamento bibliográfico e documental deste processo. Adotou-se a análise de conteúdo para a interpretação dos resultados a partir das categorias de análise: produto econômico, desenvolvimento econômico, economia criativa e dispersões do setor. Como principal resultado foi percebido, na dimensão econômica da cadeia produtiva da gastronomia criativa de Florianópolis, mais especificamente no distrito do Ribeirão da llha, um processo que foi capaz de fomentar e impulsionar atividades turísticas na região, oferecendo aos consumidores uma experiência criativa, com forte inserção da gastronomia local.

Palavras-chave: Turismo criativo. Cadeia produtiva da gastronomia. Relações econômicas. Ribeirão da Ilha. Florianópolis.

\section{ABSTRACT}

Tourism and gastronomy are enabling activities of the economy from one location. From this context, the research aimed to analyze the characteristics of the economic dimension to the productive chain of the creative gastronomy of Florianopolis and yours influences of the local tourism development. The methodology adopted the qualitative approach performing 13 interviews with actors involved in local gastronomic production chain associates to bibliographical and documentary techniques to this process. The content analysis was adopted for the interpretation of results from the categories of analysis: economic product, economic development, creative economy and dispersions. The main result was realized in the economic dimension of the productive chain of the creative gastronomy of Florianopolis, specifically in the district of Ribeirão da Ilha, a process that is able to promote and boost tourists activities in the region, offering a creative experience for consumers, with strong insertion of local gastronomy.

Keywords: Creative tourism. Gastronomic production chain. Economic relations. Ribeirão da Ilha. Florianópolis. 


\section{INTRODUÇÃo}

O turismo e a gastronomia são atividades dinamizadoras da economia de uma localidade. Os bens e serviços produzidos na perspectiva da Economia Criativa estão sempre se renovando, de acordo com o processo criativo do produtor. Essa produção estimula novos empreendedores a entrarem no mercado, não o saturando, mas diversificando a oferta (REIS, 2008).

A gastronomia pode ser considerada um importante setor criativo, visto que, além dos sabores, estão incluídos todos os saberes e fazeres de uma comunidade, gerando, com isso, um valor simbólico que posteriormente se transformará em um valor econômico para ser comercializável (DE PAULA, 2016).

Em uma escala internacional, por meio da Rede de Cidades Criativas, a UNESCO visa promover nas cidades-membro uma conexão entre campos criativos e o turismo de maneira dinâmica, sendo a gastronomia um desses campos criativos. Florianópolis faz parte dessa rede mundial sendo reconhecida pela criatividade gastronômica. Considerando a oferta de atrativos, estrutura e a demanda de fluxos turísticos, Florianópolis se destaca em Santa Catarina como categoria A do Ministério do Turismo (PIRES, QUEIROZ E RODRIGUES, 2013; FLORIPAMANHÃ, 2015, 2017; MTUR, 2017; FLORIPA CREATIVE CITY, 2017; PREFEITURA DE FLORIANÓPOLIS, 2018).

A chancela da UNESCO indica que existe um desenvolvimento da cadeia produtiva da gastronomia na região engajada na oferta do turismo de maneira criativa, a partir das perspectivas econômicas, socioculturais, espaciais e político-institucionais (FLORIPAMANHÃ, 2015, 2017; UNESCO, 2015).

A perspectiva econômica é dita como o desenvolvimento de atividades do setor turístico que abordam a gastronomia como elemento diferenciador da região capaz de agregar valor à experiência dos turistas (UNESCO, 2015; DE PAULA, 2016).

Nesse cenário, a pesquisa teve como objetivo analisar as características da dimensão econômica da cadeia produtiva da gastronomia criativa de Florianópolis e sua influência no desenvolvimento do turismo local.

Essa pesquisa se justifica pela importância em realizar estudos que identificam os benefícios gerados pela gastronomia e suas interfaces com a atividade turística, com a finalidade de trazer à luz o conhecimento a respeito da economia local. Pretende também colaborar com os estudos acerca da economia criativa a partir do segmento cultural gastronômico. 


\section{DINÂMICA DAS RELAÇÕES ECONÔMICAS}

Mello (2015) e Albernaz, Borges e Passos (2017) comentam que quando se fala em economia a ideia predominante está ligada a empresas, fábricas, lojas, supermercados, moeda, e outros segmentos. No entanto, o setor cultural provê diversos recursos econômicos para a sociedade e, dentre estes, os autores citam três como os mais importantes:

1. a cultura como recurso econômico-financeiro, no qual se reconhecem os aspectos econômicos presentes nas atividades culturais;

2. a formação de novos empregos, tanto culturais como também de pessoas que trabalham de uma maneira vinculada à cultura (trabalhadores empregados em atividades não culturais, mas necessários ao sistema de produção dos bens culturais ou dos processos de manutenção e serviço);

3. e o aumento do capital simbólico, ou seja, a percepção dos processos culturais também como geradores de riqueza social, elementos intangíveis que agregam valor adicional aos bens e serviços culturais.

O que se pode dizer é que a atividade econômica assim como as atividades política, religiosa e artística, são atividades sociais ou têm aspectos socioculturais. Afinal, a atividade econômica não envolve apenas as relações do homem com a natureza, mas, igualmente e sobretudo, as relações do homem com os outros homens. A atividade econômica diz respeito ao homem na sua atividade de produção, distribuição e consumo de bens (MELLO, 2015).

Entende-se que o enfoque da "economia cultural" se dá na aplicação da análise econômica a todas as artes criativas e cênicas, às indústrias patrimoniais e culturais. Ela se preocupa com a organização econômica do setor cultural e com o comportamento dos produtores, consumidores e governos nesse setor (UNCTAD, 2010).

A UNCTAD (2010, p. 10) entende que a "economia criativa é um conceito em evolução baseado em ativos criativos que potencialmente geram crescimento e desenvolvimento econômico". Para ela, no centro da economia criativa localizam-se as indústrias criativas. Isso pode estimular a geração de renda, criação de empregos e a exportação de ganhos, ao mesmo tempo em que promove a inclusão social, diversidade cultural e desenvolvimento humano. É capaz de abraçar aspectos econômicos, culturais e sociais que interagem com objetivos de tecnologia, propriedade intelectual e turismo. É, ainda, um conjunto de atividades econômicas baseadas em conhecimento, com uma dimensão de desenvolvimento e interligações cruzadas em macro e micro níveis para a economia em geral. É, também, uma opção de 
desenvolvimento viável que demanda respostas de políticas inovadoras e multidisciplinares, além de ação interministerial (UNCTAD, 2010).

Esses tipos de inovações, que são originadas no próprio sistema, quando introduzidas na atividade econômica, produzem mudanças que são qualitativamente diferentes daquelas alterações do dia a dia, levando ao rompimento do equilíbrio alcançado no fluxo sistêmico das cadeias produtivas. Assim, a evolução econômica se caracteriza por rupturas e descontinuidades com a situação presente e se devem à introdução de novidades na maneira do sistema funcionar (COSTA, 2006).

A UNCTAD (2010, p. 23) considera a economia criativa profundamente arraigada nas economias nacionais. Para ela:

Ao produzir benefícios econômicos e emprego nos setores de serviços e manufatura relacionados, [a economia criativa] promove a diversificação econômica, receitas, comércio e inovação. Ela ajuda a reavivar áreas urbanas, a abrir e desenvolver áreas rurais remotas e a promover a preservação dos recursos ambientais e patrimônios culturais de um país.

Nesse sentido, a UNCTAD (2010) recomenda os gestores políticos dos países a adotarem o método abrangente da Conta Satélite da Cultura (CSC) nas suas políticas econômicas que, segundo essa instituição, além de fornecer informações monetárias sobre a geração e utilização de produtos e serviços culturais, pode oferecer dados não monetários, como o número de obras produzidas ou o número de pessoas envolvidas em um evento cultural.

Os principais objetivos da CSC são (UNCTAD, 2010, p. 102):

- selecionar as práticas e produtos dos setores culturais e criar definições e classificações de acordo com os conceitos e a estrutura do Sistema Nacional de Contas;

- definir os mecanismos de geração e troca de produtos culturais e integrar essa análise às estruturas macroeconômicas existentes sem prejudicar as suas especificidades (por exemplo, nem todas as atividades culturais estão registradas nos processos de produção com valor econômico);

- demarcar os fluxos de comércio internacional que afetam os produtos culturais devido ao seu possível impacto não apenas sobre a economia, mas também sobre a preservação das identidades culturais;

- delimitar as despesas culturais totais por objeto, natureza e beneficiário: produtos e serviços que beneficiam diretamente os lares; consumo de bens, como as obras de arte originais utilizadas nos processos de produção dos produtos culturais; despesas públicas diretas com a administração cultural, etc.; 
- explorar os diferentes processos de financiamento do consumo cultural. O financiamento público, por exemplo, pode ocorrer: por meio de subsídios ou transferências às atividades desenvolvidas pelo setor público; por meio da produção direta de produtos e serviços por parte das entidades governamentais; pela simples aquisição e doação de bens culturais e criativos para o bem da comunidade, etc.;

- oferecer informações relevantes sobre as características sociais básicas relacionadas à produção cultural e sua organização, de acordo com uma categorização orientada aos produtores com base no tamanho, tipo, utilização no campo cultural e suas características, etc.;

- e fornecer informações sobre os usos, consumos e indicadores, possibilitando uma categorização da oferta e demanda de produtos culturais (quantidades não monetárias e classificação por conteúdo) e relacioná-la às variáveis econômicas dessa estrutura.

Diversas abordagens metodológicas podem ser adotadas para realizar a análise econômica das indústrias criativas. As análises a serem consideradas como referências nessa pesquisa são a análise da organização industrial, análise da cadeia de valor, análise interindustriais e análise locacional, por realizarem suas investigações em modelos de cadeias produtivas (UNCTAD, 2010).

De acordo com a UNCTAD (2010), a análise da organização industrial é a forma mais básica da análise econômica. Seu objetivo é medir as variáveis econômicas padrão em relação às quais as agências estatísticas coletam dados rotineiramente para todas as indústrias: o valor bruto da produção, o valor agregado, a formação bruta de capital fixo, os niveis de contratação das diferentes categorias de trabalho, a concentração empresarial, entre outros fatores.

A análise da cadeia de valor é um dos métodos mais objetivos e amplamente reconhecidos de analisar a estrutura econômica e a função das indústrias criativas. Em sua forma mais simples, o modelo analítico observa onde as ideias criativas iniciais são combinadas com outros insumos para produzir um produto ou serviço criativo que, depois, pode passar pelas fases adicionais de agregação de valor até entrar nos canais de marketing e distribuição e, eventualmente, chegar ao consumidor final. A força dessa abordagem é que ela é sensivel às ações e contextos individuais, especialmente das instituições, das redes e de sua governança (UNCTAD, 2010).

Na análise interindustrial, a técnica adotada para estudar suas relações econômicas é a análise de entrada-saída. Visa conhecer as maneiras pelas quais os produtos são feitos e distribuídos na economia e capturar os efeitos diretos, indiretos e induzidos de uma variedade de estímulos externos sobre as indústrias, consumidores e governos. Um aspecto importante da análise interindustrial é a possibilidade de perceber a existência de dispersões benéficas do setor criativo às outras partes da economia (UNCTAD, 2010): 
- Dispersões de conhecimento, nos quais as empresas se beneficiam das novas ideias, descobertas ou processos desenvolvidos pelas outras, por exemplo, por meio de suas atividades de P\&D;

- Dispersões de produtos, nos quais a demanda pelo produto de uma empresa aumenta como resultado do desenvolvimento de produtos de outra;

- Dispersões de rede, nos quais as empresas ganham benefícios de outras empresas localizadas nas proximidades, como na aglomeração de serviços em áreas específicas;

- Dispersões de treinamento, quando o trabalho que é treinado em uma indústria passa a outra;

- Dispersões artísticas, quando o trabalho inovador de um artista ou de uma empresa avança uma forma de arte para o benefício de outros artistas ou empresas.

Os recursos existentes para viabilizar as novas combinações já estão disponiveis na sociedade, estando empregados em atividades que compõem o fluxo sistêmico da cadeia produtiva. São as novas maneiras de combiná-los, retirando-os dos locais onde se acham empregados e alocando-os em novas atividades, que vão produzir, então, as dispersões geradas para o desenvolvimento econômico (COSTA, 2006).

Para a análise econômica locacional observa-se a articulação dos aglomerados criativos, discutidos por Porter e Kramer (2011). Essas aglomerações são concentrações geográficas de empresas interconectadas, provedores de serviços, etc., que concorrem, mas também cooperam entre si.

Deve-se considerar também nas análises econômicas do setor cultural a predominância de (UNCTAD, 2010):

- artistas autônomos, produtores individuais e empresas de pequeno e médio porte, pois as PME's muitas das quais são micro negócios ou profissionais liberais - preenchem as várias fases das cadeias de fornecimento de produtos criativos. Micro e pequenas empresas são especialmente evidentes no topo da cadeia de fornecimento (fase de criação);

- empresas corporativas de larga escala. As grandes empresas que produzem serviços e produtos criativos muitas vezes estão envolvidas em áreas que utilizam novas tecnologias de comunicação com aplicações digitais e fornecem mercados de consumidores em massa;

- instituições culturais públicas e não governamentais. Uma quantidade significativa do capital cultural móvel e imóvel de qualquer país é mantida nas instituições públicas ou não governamentais, como museus, galerias, arquivos, monastérios, santuários, prédios históricos, locais de patrimônio, etc. Além disso, muitas vezes essas instituições são depósitos de capital cultural imaterial, como no caso dos sítios de patrimônio, por exemplo, que são vinculados à sua história e aos rituais e costumes com os 
quais eles são associados. Essas instituições contribuem com produtos culturais principalmente na forma de serviços, que são consumidos pelos locais e visitantes. Em relação a esses últimos, o potencial de turismo de algumas dessas instituições pode ser fundamental. Dessa forma, na medida em que elas atraem turistas, podem conseguir causar um impacto direto ou indireto significativo na economia.

Para Costa (2006), o dinamismo do sistema econômico depende do surgimento do empreendedor como criador de novas combinações. É alguém que tem a habilidade para que o novo seja implementado.

Buscou-se, como referência, algumas atividades profissionais reconhecidas pela Classificação Nacional de Atividades Econômicas (CNAE) para contextualizar a importância econômica do setor cultural gastronômico e suas interfaces com o turismo. Nessa direção, encontraram-se atividades relacionadas à agricultura, pecuária, pesca e aquicultura. Esta seção compreende:

A exploração ordenada dos recursos naturais vegetais e animais em ambiente natural e protegido, o que abrange as atividades de cultivo agrícola, de criação e produção animal; de exploração de animais silvestres em seus habitats naturais; a pesca extrativa de peixes, crustáceos e moluscos e a coleta de produtos aquáticos, assim como a aquicultura - criação e cultivo de animais e produtos do meio aquático (IBGE, 2018).

Outra atividade reconhecida pelo CNAE é definida na seção alojamento e alimentação. Esta seção compreende as atividades de alojamento de curta duração e os serviços de alimentação. Os serviços de alojamento se caracterizam pela curta duração da disponibilidade do local de alojamento, salvo em casos de alojamentos coletivos (pensionatos, casas de estudante), tradicionalmente tratados dentro deste segmento, assim como estabelecimentos hoteleiros (IBGE, 2018).

Os serviços de alimentação têm como característica o preparo das refeições para consumo imediato, a preparação de alimentos por encomenda e a preparação de bebidas para consumo imediato. A classe restaurantes e outros estabelecimentos de serviços de alimentação e bebidas compreende as atividades de vender e servir comida preparada, com ou sem bebidas alcoólicas, ao público em geral, entre outras atividades específicas da gastronomia (IBGE, 2018).

A seção artes, cultura, esporte e recreação contém as seguintes divisões: atividades artísticas, criativas e de espetáculos; atividades ligadas ao patrimônio cultural e ambiental; atividades esportivas e de recreação e lazer. Esta seção compreende uma ampla variedade de atividades destinadas a satisfazer os interesses culturais, de entretenimento e recreativos da população. Compreende a produção e promoção de artes cênicas e espetáculos, inclusive de atuações ao vivo, as bibliotecas, arquivos, museus, jardins zoológicos e botânicos, as atividades esportivas, de recreação e lazer (IBGE, 2018). 
A divisão atividades artísticas, criativas e de espetáculos compreende a produção e promoção de artes cênicas, espetáculos e atividades complementares. Compreende também as atividades de criação artística, como a de artistas plásticos (pintores, escultores) e escritores, bem como a gestão de espaços para artes cênicas, espetáculos e outras atividades artísticas (IBGE, 2018).

A divisão atividades ligadas ao patrimônio cultural e ambiental compreende as atividades de bibliotecas e arquivos; as atividades de museus de todos os tipos, jardins botânicos e zoológicos, parques nacionais, reservas ecológicas e áreas de proteção ambiental. Esta divisão compreende também as atividades de exploração, restauração artística e conservação de lugares e prédios históricos e de outros locais de interesse cultural ou educacional (IBGE, 2018).

Na seção atividades administrativas e serviços complementares encontra-se a divisão agências de viagens, operadores turísticos e serviços de reservas. Esta divisão contém os grupos agências de viagens e operadores turísticos e serviços de reservas e outros serviços de turismo. Esta divisão compreende a atividade de agências voltadas, principalmente, à venda de viagens, de pacotes turísticos, de serviços de transporte e de alojamento, ao público em geral e a clientes comerciais. Esta divisão compreende também as atividades de organização de excursões que são vendidas em agências de viagem ou diretamente por agentes e operadores turísticos e outras atividades de serviços relacionados a viagens, inclusive serviços de reservas e de guias de turismo (IBGE, 2018).

Na seção indústrias de transformação tem a divisão fabricação de produtos alimentícios. Esta divisão contém os grupos abate e fabricação de produtos de carne; preservação do pescado e fabricação de produtos do pescado; fabricação de conservas de frutas, legumes e outros vegetais; fabricação de óleos e gorduras vegetais e animais; laticínios; entre outros (IBGE, 2018). Esta divisão compreende o processamento e transformação de produtos da agricultura, pecuária e pesca em alimentos para uso humano e animal. Esta divisão está organizada por atividades que processam e transformam diferentes tipos de produtos como carnes, pescados, leite, frutas e legumes, gorduras e óleos, grãos e produtos de moagem, etc. e compreende também a fabricação de alimentos dietéticos, alimentos enriquecidos, complementos alimentares e semelhantes (IBGE, 2018).

Na seção comércio tem a divisão comércio por atacado. 0 comércio atacadista:

Revende mercadorias novas ou usadas, sem transformação, a varejistas, a usuários industriais, agrícolas, cooperativas, comerciais, institucionais e profissionais, ou a outros atacadistas; ou atua como representante comercial ou agente do comércio na compra ou venda de mercadorias a esses usuários. Em geral, esta venda é uma etapa intermediária da distribuição de mercadorias; e está organizada para vender mercadorias em grandes quantidades (IBGE, 2018). 
Esta divisão compreende o grupo comércio atacadista especializado em produtos alimentícios, bebidas e fumo. Este grupo tem a classe comércio atacadista de carnes, produtos da carne e pescado. Esta classe compreende o comércio atacadista de carne fresca, frigorificada ou congelada, de bovinos, suínos, caprinos, ovinos, equídeos; aves e coelhos abatidos, frescos, frigorificados e congelados; peixes e outros frutos do mar frescos, frigorificados e congelados; peixes e outros frutos do mar preparados, secos e salgados (IBGE, 2018).

Essa classe tem as subclasses comércio atacadista de carnes bovinas e suínas e derivados; comércio atacadista de aves abatidas e derivados; comércio atacadista de pescados e frutos do mar; comércio atacadista de carnes e derivados de outros animais (IBGE, 2018).

\section{METODOLOGIA}

A pesquisa foi desenvolvida sob a abordagem qualitativa de caráter exploratório. Foram realizadas 13 entrevistas entre os meses de outubro e dezembro de 2017 com atores da cadeia produtiva da gastronomia de Florianópolis. Buscou-se, ainda, referências bibliográficas e documentais para dar sustentação nas análises.

As entrevistas foram elaboradas a partir de indicadores que correlacionam aspectos econômicos com cidades criativas, cadeias produtivas e turismo criativo, apoiando-se em Hansen (2004), Costa (2006), UNCTAD (2010), Landry e Hyams (2012), Mello (2015), UNESCO (2015) e Albernaz, Borges e Pasos (2017).

Para a análise das relações econômicas se considerou os benefícios advindos da Conta Satélite da Cultura com o enfoque na cadeia produtiva da gastronomia criativa na região do Ribeirão da llha.

As relações econômicas foram analisadas segundo as categorias conforme Quadro 1: Produto econômico (atividades e recursos existentes para a geração da economia), Desenvolvimento econômico (alcance e importância econômica local), Economia criativa (geração de renda por meio da cultura) e Dispersões do setor (benefícios gerados em cadeia por terceiros). 
Quadro 1 - Procedimento analítico relações econômicas

\begin{tabular}{|l|l|l|}
\hline \multirow{2}{*}{$\begin{array}{l}\text { Categorias de } \\
\text { análise }\end{array}$} & \multicolumn{2}{|l|}{ Procedimento analítico } \\
\cline { 2 - 3 } & $\begin{array}{l}\text { Unidade de análise } \\
\text { (palavras-chave e/ou sentenças } \\
\text { propositivas) }\end{array}$ & $\begin{array}{l}\text { Indicadores } \\
\text { (fatos / ações / relações) }\end{array}$ \\
\hline Produto econômico & $\begin{array}{l}\text { Identidade; } \\
\text { Recursos existentes; } \\
\text { Posicionamento no mercado. }\end{array}$ & $\begin{array}{l}\text { Atividades e recursos existentes } \\
\text { percebidos. }\end{array}$ \\
\hline $\begin{array}{l}\text { Desenvolvimento } \\
\text { econômico }\end{array}$ & $\begin{array}{l}\text { Abrangência; } \\
\text { Exploração econômica; } \\
\text { Competitividade }\end{array}$ & $\begin{array}{l}\text { Alcance e importância econômica local } \\
\text { percebida. }\end{array}$ \\
\hline Economia criativa & $\begin{array}{l}\text { Empreendedorismo cultural; } \\
\text { Inovação. }\end{array}$ & $\begin{array}{l}\text { Geração de renda por meio da cultura } \\
\text { percebida. }\end{array}$ \\
\hline Dispersões do setor & $\begin{array}{l}\text { Promoção da gastronomia; } \\
\text { Promoção do turismo; } \\
\text { Projetos futuros }\end{array}$ & Benefícios gerados em cadeia percebidos. \\
\hline
\end{tabular}

Fonte: Elaborado pelos autores, 2018, a partir de Richards, 2010, 2015, 2017; Hansen, 2004; Costa, 2006; UNCTAD, 2010; Reis, 2011; Porter e Kramer, 2011; Landry e Hyams, 2012; Mello, 2015; UNESCO, 2015; Albernaz, Borges e Passos, 2017; IBGE, 2018

As informações foram tratadas e interpretadas por meio de uma análise crítica que seguiu os objetivos da pesquisa e teve por base estruturas teóricas fundamentadas em Costa (2006); UNCTAD (2010); Mello (2015); Albernaz, Borges e Passos (2017); e IBGE (2018).

Os resultados foram interpretados por meio da análise de conteúdo (BARDIN, 2002) construíndo um quadro síntese, tendo como objeto de estudo a dimensão econômica demonstrada na cadeia produtiva da gastronomia criativa do Ribeirão da llha. O procedimento analítico compreendeu três fases:

(1) estabelecimento de uma unidade de análise indexada segundo um quadro temático (palavraschave e/ou sentenças propositivas de cada entrevistado) sistematizando as ideias iniciais;

(2) determinação de indicadores (atributos) de análise (temas / fatos / participação / iniciativa / ações / relações / interesse do entrevistado perante a inclusão da cidade na UCCN / conhecimento da gestão do turismo criativo da cidade) com descrição analítica; 
(3) tratamento dos dados e interpretação (análise crítica segundo os objetivos e estruturas teóricas fundamentadas para tornar os dados significativos a partir de COSTA, 2006; UNCTAD, 2010; LANDRY E HYAMS, 2012; MELLO, 2015; UNESCO, 2015; ALBERNAZ, BORGES \& PASSOS, 2017; IBGE, 2018).

\section{PRODUTO ECONÔMICO DA REGIÃO DO RIBEIRÃO DA ILHA}

A economia da região de Florianópolis tem como alicerce as atividades do comércio, da pesca, prestação de serviços públicos, indústria de transformação, tecnologia, informática e turismo (FLORIPA CREATIVE CITY, s/d; ICES BRASIL, 2015; PREFEITURA DE FLORIANÓPOLIS, 2018).

A agenda estratégica de desenvolvimento sustentável da região de Florianópolis destaca os aspectos econômico-produtivos com o reconhecimento das centralidades dominantes como a existência de capital intelectual que permite o desenvolvimento empresarial alternativo, a possibilidade de uma nova, criativa e mais diversificada oferta turística, de base ecológica e cultural e uma importante oferta de paisagem natural e cultural, sendo a gastronomia uma possível conexão para essas variáveis (COSTA, 2006; FLORIPAMANHÃ, 2008).

A gastronomia e a maricultura são destacadas como parte de um dos eixos do programa de incentivos às atividades econômicas dinamizadoras da região de Florianópolis, sendo atividades que tangenciam o desenvolvimento local. 0 distrito do Ribeirão da llha faz parte das regiões que oferecem essa cadeia produtiva. A partir da produção da maricultura, Florianópolis se destaca no Brasil por oferecer aproximadamente $90 \%$ do insumo que é consumido no país. Em 2009, foram produzidos no Estado mais de 12 mil toneladas de ostras, mexilhões e vieiras, proporcionando uma movimentação financeira bruta estimada em mais de R\$21 milhões para o Estado. Além do mercado local, os moluscos catarinenses abastecem grandes mercados, como Rio de Janeiro e São Paulo. Santa Catarina é o segundo maior produtor da América Latina, ficando atrás apenas do Chile (FLORIPAMANHÃ, 2008; PIRES; QUEIROZ; RODRIGUES, 2013).

De acordo com Mondo e Borges (2014), o distrito de Ribeirão da Ilha é citado como responsável por 80\% da produção de ostras de Florianópolis, sendo esta uma importante atividade econômica da região, corroborando o que relata um entrevistado:

A ostra não só desenvolveu pessoas da própria região que viram ali uma oportunidade de trabalho e de renda... porque na medida que o pescador artesanal e o peixe foi acabando... ele ficou sem trabalho... e viram na ostra, na criação de ostra... uma oportunidade de trabalho. 
Na região do Ribeirão da llha a economia, em seus primeiros anos, era baseada na agricultura, na pesca e na produção artesanal de alguns artefatos de uso doméstico. Tais aspectos produtivos não se alteraram muito no século XIX e início do século XX, em parte por conta do isolamento que esta localidade tinha em relação às demais. Suas relações com Desterro (antigo nome de Florianópolis) eram, em sua maioria, motivadas pelo comércio (SILVA, 2012; IPHAN/SC, 2015).

A mudança da atitude de extração tradicional para a maricultura e ostreicultura em fazendas marinhas da região do Ribeirão da llha tem tornado lucrativa essa atividade atraindo investidores pelo aumento da renda familiar proporcionada pelo baixo investimento e curto prazo para o retorno da produção (MONDO; BORGES, 2014).

A maricultura iniciou em Florianópolis entre as décadas de 1970 e 1980, por meio da cooperação entre pescadores e instituições como a Universidade Federal de Santa Catarina (UFSC) e a Empresa de Pesquisa Agropecuária e Extensão Rural de Santa Catarina (EPAGRI-SC), tornando-se destaque como produto econômico local. Considerada como fonte de renda para as comunidades pesqueiras da região, provocou mudanças na economia do litoral catarinense, que reúne condições adequadas para o cultivo de moluscos: baías e enseadas ricas em fitoplâncton e com temperaturas adequadas. A tecnologia desenvolvida por instituições como a UFSC também contribui para o aprimoramento desse cultivo (SILVA, 2012; PIRES; QUEIROZ; RODRIGUES, 2013; EPAGRI, 2015).

\section{DESENVOLVIMENTO ECONÔMICO DA REGIÃO DO RIBEIRÃO DA ILHA}

Atualmente, estão diretamente envolvidos na maricultura em Santa Catarina cerca de 690 maricultores, representados pela Associação Catarinense de Aquicultura (ACAq), pela Federação das Empresas de Aquicultura (FEAq), por 28 associações municipais e três cooperativas. São mais de 4 mil empregos indiretos. Além de produzirem pescado artesanalmente, alguns maricultores, submetidos ao Serviço de Inspeção Federal (SIF), comercializam para todo o país moluscos in natura e processados dinamizando o mercado da maricultura. Percebendo um novo nicho de mercado, muitos produtores passaram a comercializar o produto diretamente ao consumidor, tornando-se empreendedores da gastronomia, como é o caso de alguns restaurantes das comunidades de Ribeirão da Ilha, Sambaqui e Santo Antônio de Lisboa (PIRES; QUEIROZ; RODRIGUES, 2013; EPAGRI, 2015).

A maricultura tem se constituído em uma atraente alternativa em diferentes localidades catarinenses perante as dificuldades da pesca artesanal, a julgar pela progressão da quantidade produzida, sintoma da multiplicação dos contingentes envolvidos e das áreas de cultivo. Essa expansão tem representado novas oportunidades de trabalho, embora prevaleça o envolvimento da mão-de-obra familiar, com a utilização 
de pessoas contratadas como constataram diferentes estudos de campo da EPAGRI. Esse engajamento é informal e oportuniza indivíduos das próprias comunidades. Vale assinalar que as mulheres tendem a se concentrar nas atividades de beneficiamento (os moluscos são cozidos, desconchados, pesados e embalados em sacos plásticos) e que aos homens são geralmente atribuídas as tarefas ligadas à produção (instalação das estruturas de cultivo, manejo e colheita), embora sem exclusividade (EPAGRI, 2015).

Dado à sua importância para a região, tem potencial para incluir dos pequenos produtores, seja de forma associada ou isolada, no processo de evolução tecnológica e formalização da cadeia produtiva. Além da inclusão, esta estratégia pode contar com um grande esforço em programas educativos e esclarecedores para produtores, comerciantes e consumidores, bem como ações de fiscalização, para gradativamente educar a população quanto aos benefícios do comércio e do consumo seguro de moluscos. Os objetivos de desenvolvimento econômico somente poderão ser atingidos com algum grau de especialização bem como de melhor integração entre os elos da cadeia produtiva (EPAGRI, 2015).

O cultivo e comercialização de ostras e mariscos, segundo Nor (2010), intensificou o desenvolvimento econômico na região a partir da abertura de restaurantes, tornando o Ribeirão da llha um destacado centro gastronômico especializado em frutos do mar. Para a autora, essas atividades associadas às belezas naturais e ao casario ${ }^{1}$ histórico preservado têm impulsionado o turismo local. Isso se reforça na fala de um entrevistado quando diz que "a questão da gastronomia é muito rica na cidade... não é só ir no restaurante e comer... é reconhecer a produção das ostras, a produção da cachaça, a cerveja que é tão forte aqui agora e daí ele poder fazer isso". Essa fala indica a possibilidade de agregar valor ao produto ostra, envolvendo aspectos característicos do turismo criativo a partir da culinária.

No mesmo sentido, outro entrevistado diz que é possível promover o desenvolvimento econômico por meio de produtos criativos na região de Florianópolis:

Sem dúvida que dá pra criar produtos mais experienciais/criativos... estou tomando isso como sinônimo... criativo no sentido de diferente... de participativo... acho que é isso aí... o pisar na uva para fazer o vinho.... faz parte... acho que o exemplo perfeito de Florianópolis é o Ostra Experience... acho que são coisas que agregam bastante no destino. E Florianópolis precisa muito disso porque se pegarmos de 10 a 15 anos para cá... nós não temos novidades... o produto turístico é o mesmo.

Um quarto entrevistado informa que já se trabalha o turismo criativo na região de Florianópolis,

\footnotetext{
${ }^{1}$ Conjunto histórico formado por casas geminadas, a maioria alinhada na via, em frente ao mar e ao redor da praça central, onde se encontra a Igreja Matriz. Fonte: http://www.caminhodasostras.com.br/paginas/cultura/casario.html
} 
considerando a cultura como recurso econômico-financeiro. Segundo Mello (2015) e Albernaz, Borges e Passos (2017) se reconhecem os aspectos econômicos presentes nas atividades culturais, assim como se percebe o aumento do capital simbólico, ou seja, a percepção dos processos culturais também como geradores de riqueza social, elementos intangíveis que agregam valor adicional aos bens e serviços culturais. De acordo com o mesmo entrevistado:

A gente tem trabalhado na divulgação da gastronomia de experiência... inclusive nessa
versão do guia eletrônico a gente vai ter uma categorização... a gente criou categorias de
tipos de experiências divulgando isso e hoje a gente já vê em vários estabelecimentos
que trabalham isso com excelência e é um ponto de inovação e é um ponto de bastante
interesse não só pelo turista mas pelo morador também do município... muitas vezes
querer saber o que tem de novo. Vai ser lançado no mês de dezembro. Mas a gente
já vem ao longo de todo ano trabalhando a gastronomia de experiência... a gente fez
várias palestras... o quê que é... a divulgação de cases... que tem já a gastronomia de
experiência sendo praticada.

Analisando sob o viés do desenvolvimento econômico, a ostra é fundamental para a região. Além dos restaurantes, existem os produtos culturais da região e o próprio produto ostra tem se tornado atrativo turístico. Os maricultores têm utilizados seus barcos para realizarem passeios com os turistas para mostrarem o cultivo da ostra, o processo produtivo e a degustação tornando a ostra uma experiência turística de forma criativa (MONDO; BORGES, 2014).

No entanto, as entrevistas relataram alguns problemas que atrapalham o desenvolvimento econômico local, como, por exemplo, o entendimento da fraca relação da pesca com o turismo. De acordo com outro entrevistado, essa relação:

Poderia ser mais explorada. Fraca em tudo. Estamos trabalhando para isso... isso somaria para o turismo, para os pescadores... hoje nós temos uma beira mar norte que desaba.... se for em outros países vê que o mercado público que vende peixe é na beirada. Aí para vender um peixe aqui é um martírio. Dizem que aqui é a terra do turismo mas a gente não pode fazer um trapiche... tudo por lei federal... não pode fazer isso... então hoje nós estamos virados de costa para o mar. Poderíamos ter em cada praia um movimento turístico com uma bancada de peixe, com certificação... algo que tenha ali perto para resfriar os peixes... e hoje nós não temos! Imagina vai ali pega o peixe do pescador e leva pra tua casa... a beira mar o que que é hoje? Para andar, comer milho verde e tomar água de coco! Apenas isso! É vergonhoso! 
Por outro lado, um projeto que deu certo e que ajuda a valorizar o comércio local aumentando o consumo do pescado e ao mesmo tempo criando um hábito alimentar na região é o caminhão do peixe que, segundo um entrevistado:

\begin{abstract}
O caminhão do peixe já existe alguns anos em Florianópolis... desde 2011... esse ano ele veio reformulado com produto 100\% manezinho. Só vai no caminhão produtos de empresas de Florianópolis. Tentando valorizar os pescadores... a produção local. 0 objetivo é criar... apesar de sermos uma cidade litorânea... poucas pessoas consomem pescado... é uma coisa brasileira... o consumo é baixo... então o caminhão do peixe leva em alguns bairros priorizando aqueles de baixa renda... é um convênio que temos com a federação de pescadores... o caminhão foi cedido pelo Ministério da Agricultura. Então leva o pescado com um preço mais acessivel que o de mercado normal e para fomentar esse consumo para criar o costume de ter peixe toda semana na mesa.
\end{abstract}

Essa ação específica demonstra que existem ideias e projetos na região com o objetivo de disseminar o comércio gastronômico de uma forma itinerante e inclusiva, aproximando o produtor do consumidor nos mais variados bairros de Florianópolis, o que pode, consequentemente, ampliar o desenvolvimento econômico local.

\title{
5 ECONOMIA CRIATIVA NA REGIÃO DO RIBEIRÃO DA ILHA
}

Com base na perspectiva da economia criativa, um entrevistado informou que o governo local se atenta às questões que conectam cultura e economia e estão mobilizando ações nesse sentido. Uma das ações relatadas diz respeito à aproximação da economia criativa com o turismo. De acordo com um entrevistado:

Do ponto de vista do turismo a gente chamou pra fazer parte do Conselho Municipal de Turismo a pessoa que coordena o núcleo de economia criativa da Associação Comercial e Industrial de Florianópolis... e a intenção é unir, integrar, criar sinergia... o pessoal do Centro Sapiens sempre parceiro das ações de economia criativa... quer dizer... é unir o turismo com o pessoal da economia criativa para ver o que traz de bom e trazer tecnologia junto já que a gente é referência nacional das empresas de tecnologia vamos ver se a gente consegue fazer um mix.

Além dessas ações da esfera política, outro entrevistado comentou que há um programa institucional que visa desenvolver projetos com foco na promoção da economia criativa. Segundo um entrevistado: 
No planejamento tem hoje o programa SENAC criativo... é um programa novo no SENAC, mas ele atua exatamente na economia criativa fazendo com que as cidades, as pessoas, os moradores consigam desenvolver projetos naquela cidade para a geração de renda, mas tudo voltado a essa economia... então esse seria nosso grande projeto hoje de economia criativa.

Reforçando a ideia de desenvolver a economia criativa na região, um terceiro entrevistado relatou que o setor público local pretende criar arranjos produtivos baseados na tecnologia. De acordo com um entrevistado:

Existe na secretaria um esforço bastante grande... a criação da API (Arranjos Produtivos e Inovação) do turismo e economia criativa... e como a tecnologia também está aqui a gente criou e a intenção é justamente redes de turismo e economia criativa.

Esse arranjo produtivo e inovação podem contribuir significativamente para o desenvolvimento das redes de relacionamento da cadeia produtiva da gastronomia local. A inovação já está presente na culinária local, e conforme Mondo e Borges (2014) salientam, apesar da ostra não ser um legado cultural dos antepassados do território, foi uma inovação que se encaixou perfeitamente no estilo de vida dos moradores da região e se tornou uma das mais fortes identidades culturais e econômicas do território, o que faz com que estimule a economia criativa e que os moradores locais deem credibilidade para as instituições tecnológicas da região.

A gastronomia dentro da economia criativa é importante não apenas pelo viés da alimentação, mas pelo vetor de sociabilidade, da recuperação, da expressão de uma cultura, da sustentabilidade, da qualidade alimentar, da inclusão e da relação entre tecnologia e o artesanal (LEITÃO, 2018).

Atrelada às atividades pesqueiras encontra-se a produção da renda de bilro, bastante tradicional na região e que também faz parte da cadeia produtiva. Parte das heranças culturais dos açorianos, a renda de bilro se estabeleceu na llha e continuou presente ao longo do processo de ocupação das freguesias. Geralmente confeccionada por mulheres e filhas de pescadores, que atualmente têm nesta atividade uma forma de geração de renda, em função da fama que adquiriu em todo o país (IPHAN/SC, 2015).

No entanto, foi percebido um descompasso do setor público em relação à divulgação dos eventos ligados diretamente à economia criativa da gastronomia local. Segundo um entrevistado, a instituição promove diversas ações de marketing da região para diversos públicos, mas percebe que o governo estadual não colabora com essas ações: 
A gente se envolve... toda parte de divulgação, redes sociais, nas newsletters que mandamos para 600 e-mails, tanto associados como imprensa e trade turístico... a gente precisa de produtos em Florianópolis... Floripa nas quatro estações... então porque que eu posso trazer pessoas aqui que vão vir para oktober e porque que eu não posso incluir a FENAOSTRA no meio do caminho? Então a gente precisa reconhecer a FENAOSTRA... recebi a newsletter de uma entidade estadual que fala da marejada, da oktober, de outras festas, a sede da Entidade é em Florianópolis... e não falou da FENAOSTRA.

Esse mesmo entrevistado pontuou outras dificuldades encontradas na região de Florianópolis que atrapalham o desenvolvimento da economia criativa local. Ele destacou a falta de dados e informações dos benefícios gerados pelo turismo. Para ele, é preciso que:

A própria prefeitura reconheça o turismo como uma das principais economias de Florianópolis. Outro grande problema: dados, informação... a gente precisa saber quanto que o turismo gera de imposto. Quanto que os turistas estão deixando na cidade? Quanto de receita isso está gerando... emprego... mas temos a dificuldade até nos hotéis... eles não passam informação correta da ocupação, a realidade. Dados, informação... é a nossa maior dificuldade.

Outro relato constatado a respeito das dificuldades em desenvolver a economia criativa na região menciona que:

A questão da economia criativa é um discurso que procuramos fazer junto a câmara de vereadores, junto aos segmentos da prefeitura e no setor empresarial..., mas não é um discurso popular, não foi assimilado pelos segmentos da sociedade. As pessoas ainda percebem assim... as tecnologias mudam o mundo... a criatividade é fundamental..., mas como transformar isso em uma ação bastante prática... a sociedade não tem esses instrumentos ainda... acho que a gente não tem sido competente ... nem nós, nem os órgãos públicos.

Por outro lado, um entrevistado comentou sobre como o governo local está tentando fomentar o desenvolvimento da economia criativa da região de Florianópolis. Segundo ele:

Nós temos, em Florianópolis, a lei de incentivo à cultura que ela é uma renúncia de receita do município no valor... pode ser $20 \%$ do ISS da empresa ou $20 \%$ do IPTU. Esse ano já liberamos em torno de $\mathrm{R} \$ 2$ milhões para finalizar projetos de cultura. Esses financiamos pode chegar até $\mathrm{R} \$ 200$ mil não podendo o mesmo proponente ter mais de dois projetos... Só pode captar empresas da região. Qualquer projeto... apresentou o 
projeto ele tem que ser realizado no município. Não precisa nem de CNPJ, pessoa física pode propor... então a ideia é que por vezes o artista ele não está organizado numa empresa, mas ele tem o direito de acessar o recurso da cultura. Então essa foi uma forma que nós encontramos também de dar uma vazão à demanda que nós temos de financiamentos da cultura local... da cultura como um todo.

Na mesma direção, outro entrevistado também apresentou uma ação que auxilia o empreendedor criativo da região de Florianópolis:

Além de turismo, a gente engloba tecnologia e desenvolvimento econômico... então a parte de desenvolvimento econômico, uma das ações importantes que foi criada para fomentar a economia é justamente a parte da prefeitura auxiliar o empreendedor, a gente disponibiliza ao pequeno empreendedor um recurso em forma de empréstimo... onde o empreendedor pode chegar à prefeitura poder fazer esse empréstimo... ele tem doze anos para pagar sendo que o último pagamento é feito pela prefeitura... então ele consegue injetar dinheiro no caixa dele, para ele poder trabalhar com esse dinheiro.

Além do incentivo financeiro, um entrevistado comentou outra ação que o governo local promove que visa auxiliar os produtores locais a realizarem atividades que podem gerar um impulso na economia ao mesmo tempo em que valoriza a cultura local. Ele diz que no mercado público:

Tínhamos um local que era um restaurante e depois se transformou, na administração passada, na sala de atos do prefeito... uma área nobre e, na nossa visão, desperdiçada. Falamos com o prefeito e pedimos para transformar aquilo numa galeria de artes tradicional... e é a galeria de artes de maior sucesso em Florianópolis. Já funcionou uma exposição... só de artistas locais... nós temos privilegiado os artistas locais... o mercado tem a coisa de Florianópolis... dar oportunidade... ninguém paga nada... a gente dá toda estrutura... nós vamos buscar na casa dele... nós damos segurança... nós damos tudo para ele. Para valorizar o nosso artista local.

Uma forma encontrada para auxiliar os artistas locais a comercializarem seus produtos, segundo um entrevistado, é aproximá-los aos empreendedores culturais da cidade. Segundo ele:

O artista não consegue vender porque essa não é sua melhor habilidade. E é muito difícil capacitar o artista para ser empreendedor cultural... então é mais fácil ter o empreendedor cultural, que é alguém da cultura, do que insistir em capacitar quem não tem habilidade para isso. Ele é bom no que faz. Mas não consegue vender sua arte, esse produto. Então estamos trabalhando muito com os empreendedores. 
Essa parceria entre empreendedores culturais e artistas, se bem administrada, pode ser interessante para as duas partes, pois é capaz de reunir quem tem competência para organizar eventos, feiras e comercialização de produtos com os produtores de cultura e arte local, sendo o motor da economia criativa.

\section{DISPERSÕES GERADAS PELO SETOR GASTRONÔMICO DA REGIÃO DO RIBEIRÃO DA ILHA}

A importância da educação para o desenvolvimento da economia local foi destacada nas entrevistas. Segundo um entrevistado, o foco de atuação da instituição é capacitar as pessoas para profissionalizar a gastronomia, o que pode gerar uma dispersão do conhecimento para todos os envolvidos na cadeia produtiva. Uma das entrevistadas relatou o foco de atuação na gastronomia:

Nosso foco na questão da gastronomia são as escolas... através do SENAC... porque enxergamos gerador de emprego e renda... gerador de pessoas que querem seu próprio negócio... por exemplo estuda, faz curso no SENAC... a gastronomia sobre o olhar do comércio é fundamental. Porque toda a cadeia produtiva dos restaurantes, dos bares... eles precisam ser alimentados... aí quem alimenta o produto final que é o prato na mesa do consumidor? É o comércio! Isso tem um giro fortíssimo! Tanto em relação aos supermercados quanto atacadistas, fornecedores de produtos orgânicos... é uma cadeia longa, extensa, mas ela está mapeada. No grupo gestor da UNESCO estamos mapeando essa cadeia. Está sendo mapeada.

Outra questão importante destacada nas entrevistas foi a parceria entre os empreendimentos gastronômicos da região de Florianópolis. Um entrevistado citou uma ação que potencializa a geração de negócios e estimula a troca de informações entre os associados, o que fortalece a cadeia produtiva local:

A gente faz uma ação entre os associados que chama rodada de negócios. São dois momentos em que eles podem se encontrar... tem os eventos mais festivos, mas tem essa rodada de negócios entre os associados. Então eles sentam para conversar... toda essa cadeia senta para conversar com centro de convenções e organizadoras de eventos, que são aqueles que indicam o que contratam... realizado uma vez por ano. Nós temos um outro que chama café de oportunidades, onde realizamos por região em Florianópolis. A gente apresenta ações que já alcançamos e que ainda temos até o final do ano e ali cada empresa tem dois minutos para se apresentar. 0 que que é bom? Uma agência se apresenta para empresas como restaurantes, empresa de organização esportiva, e por aí vai... então eles conhecem todo mundo.

Além dessa ação, o mesmo entrevistado comentou que também há uma ação mais informal, mas que também apresenta bons resultados para os associados e que também pode ser considerada 
uma dispersão de conhecimento, no qual empresários se beneficiam das novas ideias, descobertas ou processos desenvolvidos pelos outros (UNCTAD, 2010). Segundo este entrevistado:

\footnotetext{
A gente tem um evento que chama happy hour com conhecimento, que é um evento itinerante que sempre acontece na casa de um associado onde o anfitrião conta um pouquinho da sua história, compartilha informações, compartilha conhecimento e depois acontece um happy hour justamente para ter essa troca... de informação... e tudo isso propicia muita riqueza na gestão dos estabelecimentos.
}

Em relação à certificação de qualidade do produto, um entrevistado comentou que há dificuldades, mas é possivel melhorar isso na cadeia produtiva da região de Florianópolis trabalhando o serviço de inspeção municipal. De acordo com ele:

\footnotetext{
O grande problema que a gente tem... $80 \%$ das ostras, poucas dessas são certificadas... então um dos grandes avanços écriar nesses pescadores, eaté mesmo nos restaurantes, esse lado empresário... que eles deixam de ser o pescador ali o maricultor... e ele vai levar essa ostra certificada criando uma valorização dali, com inspeção municipal. Por exemplo, o Paraíso das Ostras tem o SIM 001..., mas também precisa levar para o pescador... então esse é o grande avanço. É levar para eles esse serviço valorizando aquele produto que ele já tem bom... até mesmo legalizando aquilo ali. Essa é a parte que a gente trabalha levando essa parte... empreender eles... tirar essa visão de que o pescador só fica ali na praia de chinelinho... que ele pode ser um empresário... ele pode fazer as duas coisas. Valorizando eles.
}

Embora a fala anterior lamente a falta de fiscalização e controle de qualidade, outro entrevistado afirmou que uma das ações futuras na região do Ribeirão da llha é esse controle. Segundo este outro entrevistado "vai ter a inspeção municipal... e ela regula a cadeia gastronômica do Ribeirão... cria a oportunidade de certificar as ostras e os moluscos." Consequentemente, isso irá gerar uma dispersão de qualidade para toda cadeia produtiva da gastronomia.

\section{AS RELAÇÕES ECONÔMICAS DA GASTRONOMIA DA REGIÃO DO RIBEIRÃO DA ILHA, FLORIANÓPOLIS}

A criação, a produção e a distribuição são as etapas nas quais se identificam com mais clareza os fundamentos da Economia Criativa. Apesar da necessidade de obedecer a determinados padrões de qualidade, há um processo criativo que antecede as etapas principais do ciclo, algo intrínseco à gastronomia. 
Tudo começa com a criação de um modelo de negócio que permite a exploração de uma via alternativa de acesso ao mercado. A criação e a produção do bem, então, dependem da capacidade de aplicação da criatividade, do conhecimento, da técnica e da cultura (SEABRA, 2017).

No âmbito econômico, o segmento turístico gastronômico permite dinamizar a economia local, por meio da criação de uma rede de negócios que envolve diversos atores (produtores, fornecedores, chefes, agentes turísticos, entre outros) na produção e venda de produtos característicos da gastronomia local (MARTINS; GURGEL; MARTINS, 2016).

Segundo as entrevistas realizadas com os atores locais, é possivel apresentar um quadro analítico a respeito das relações econômicas da cadeia produtiva da gastronomia criativa da região (quadro 2).

\section{Quadro 2 - Síntese das relações econômicas da gastronomia de Florianópolis}

\begin{tabular}{|c|c|c|}
\hline \multirow[b]{2}{*}{ Categorias de Análise } & \multicolumn{2}{|l|}{ Procedimento analítico } \\
\hline & $\begin{array}{l}\text { Unidade de análise } \\
\text { (palavras-chave elou sentenças } \\
\text { propositivas) }\end{array}$ & $\begin{array}{l}\text { Indicadores } \\
\text { (fatos / ações / relações) }\end{array}$ \\
\hline Produto econômico & $\begin{array}{l}\text { Comércio, pesca, prestação } \\
\text { de serviços públicos, indústria } \\
\text { de transformação, tecnologia, } \\
\text { informática e turismo; } \\
\text { Gastronomia e a maricultura. } \\
\text { Produção de ostras. }\end{array}$ & $\begin{array}{l}\text { Existência de capital intelectual que } \\
\text { permite o desenvolvimento empresarial } \\
\text { alternativo, a possibilidade de uma } \\
\text { nova, criativa e mais diversificada oferta } \\
\text { turística, de base ecológica e cultural } \\
\text { e uma importante oferta de paisagem } \\
\text { natural e cultural, sendo a gastronomia } \\
\text { uma possível conexão para essas } \\
\text { variáveis; } \\
\text { Atividades que tangenciam o } \\
\text { desenvolvimento local; } \\
\text { Ribeirão da Ilha é responsável por } 80 \% \text { da } \\
\text { produção de ostras de Florianópolis. }\end{array}$ \\
\hline $\begin{array}{l}\text { Desenvolvimento } \\
\text { econômico }\end{array}$ & $\begin{array}{l}\text { Associação Catarinense de } \\
\text { Aquicultura (ACAq), pela Federação } \\
\text { das Empresas de Aquicultura (FEAq), } \\
\text { por } 28 \text { associações municipais e três } \\
\text { cooperativas; } \\
\text { Evolução tecnológica e formalização } \\
\text { da cadeia produtiva; } \\
\text { destacado centro gastronômico } \\
\text { especializado em frutos do mar. }\end{array}$ & $\begin{array}{l}\text { Mais de } 4 \text { mil empregos indiretos; } \\
\text { Empreendedores da gastronomia; } \\
\text { Oportunidades de trabalho; } \\
\text { Programas educativos, especialização e } \\
\text { integralização na cadeia produtiva; } \\
\text { Agregar valor ao produto ostra, } \\
\text { envolvendo aspectos característicos do } \\
\text { turismo criativo a partir da culinária. }\end{array}$ \\
\hline
\end{tabular}




\begin{tabular}{|c|c|c|}
\hline Economia criativa & $\begin{array}{l}\text { Governo local se atenta às questões } \\
\text { que conectam cultura e economia; } \\
\text { Projetos com foco na promoção da } \\
\text { economia criativa; } \\
\text { Descompasso do setor público em } \\
\text { relação à divulgação dos eventos } \\
\text { ligados diretamente à economia } \\
\text { criativa da gastronomia local; } \\
\text { Falta de dados e informações dos } \\
\text { benefícios gerados pelo turismo; } \\
\text { Dificuldades em desenvolver a } \\
\text { economia criativa; } \\
\text { Fomento da economia criativa. }\end{array}$ & $\begin{array}{l}\text { Unir o turismo com o pessoal da } \\
\text { economia criativa para ver o que traz de } \\
\text { bom e trazer tecnologia junto; } \\
\text { Programa SENAC criativo; } \\
\text { Falta de divulgação específica da } \\
\text { FENAOSTRA; } \\
\text { Dúvidas na geração de receita; } \\
\text { A economia criativa não é um } \\
\text { discurso popular, a sociedade não tem } \\
\text { instrumentos; } \\
\text { Lei de incentivo à cultura, incentivo } \\
\text { financeiro ao empreendedor, } \\
\text { disponibilidade de espaço público. }\end{array}$ \\
\hline Dispersões do setor & $\begin{array}{l}\text { Educação para o desenvolvimento } \\
\text { da economia local; } \\
\text { Parceria entre os empreendimentos } \\
\text { gastronômicos; } \\
\text { Ação entre associados; } \\
\text { Certificação de qualidade do } \\
\text { produto. }\end{array}$ & $\begin{array}{l}\text { Capacitar as pessoas para profissionalizar } \\
\text { a gastronomia; } \\
\text { Fortalecimento da cadeia produtiva local; } \\
\text { Novas ideias, descobertas ou processos; } \\
\text { Há dificuldades, mas é possível melhorar } \\
\text { pela cadeia produtiva. }\end{array}$ \\
\hline
\end{tabular}

Fonte: Elaborado pelos autores, 2018

Em síntese, a análise das relações econômicas da gastronomia de Florianópolis, especificamente no Ribeirão da Ilha, demonstrou que os aspectos relacionados ao produto econômico, desenvolvimento econômico, economia criativa e dispersões do setor giram em torno do produto gastronômico voltado para a maricultura, dimensionando toda uma cadeia produtiva local (UNCTAD, 2010; MELLO, 2015; ALBERNAZ; BORGES; PASSOS, 2017).

A dimensão econômica da cadeia produtiva da gastronomia criativa local promove e influencia o turismo criativo na região do Ribeirão da llha, pois foi percebido que os atores envolvidos agregam valor ou se preocupam em melhorar os elos da cadeia, com vistas a oferecer aos consumidores uma culinária criativa com aspectos da cultura local (REIS, 2008; RICHARDS, 2015; DE PAULA, 2016; MARTINS; GURGEL; MARTINS, 2016).

Foi percebido que a gastronomia como produto cultural é capaz de dinamizar a economia local provendo diversos recursos para a sociedade. As atividades criativas desenvolvidas a partir da gastronomia, como o turismo criativo, movimentam a economia e dão condições para novas conexões sistêmicas no setor produtivo (MELLO, 2015; ALBERNAZ; BORGES; PASSOS, 2017). 
Portanto, a gastronomia como produto criativo é capaz de abraçar aspectos econômicos, culturais e sociais que interagem com objetivos de tecnologia, propriedade intelectual e turismo, criando novas conexões com cadeias produtivas distintas. Isso se reconhece como um conjunto de atividades econômicas baseadas em conhecimento, com uma dimensão de desenvolvimento e interligações cruzadas em macro e micro níveis para a economia em geral. Desse modo, a gastronomia é uma opção de desenvolvimento viável que demanda respostas de políticas inovadoras na construção de cadeias produtivas criativas e multidisciplinares (UNCTAD, 2010).

Como resultado desse estudo, identificou-se que a dimensão econômica da cadeia produtiva da gastronomia de Florianópolis, com foco no Ribeirão da llha, é capaz de promover o desenvolvimento de atividades criativas, confirmando as teorias utilizadas. Desse modo, no contexto econômico, a cadeia produtiva da gastronomia criativa dá condições para o reconhecimento de uma cidade criativa da UNESCO (UNCTAD, 2010; SEABRA, 2017).

\section{CONSIDERAÇÕES FINAIS}

Na análise da dimensão econômica de Florianópolis foi possivel constatar o que afirma Costa (2006), que inovações inseridas nas cadeias produtivas da gastronomia da região, originadas nos próprios sistemas e pelos stakeholders locais, produzem mudanças que são qualitativamente diferentes daquelas alterações decorrentes do dia a dia, levando ao rompimento do equilîbrio alcançado no fluxo sistêmico. Com isso, o desenvolvimento econômico da cadeia produtiva criativa local se caracteriza por rupturas e descontinuidades do contexto atual e se devem à introdução da pesquisa e inovação de novas maneiras de compreender a culinária dentro do sistema, refletindo tanto na cultura local quanto na oferta do turismo criativo.

Percebeu-se que em Florianópolis o enfoque da economia cultural está presente nas políticas públicas locais. As instituições da região se preocupam com a organização econômica do setor cultural e com o comportamento do setor público, dos produtores e consumidores nesse setor, especificamente no caso estudado da gastronomia, o que vai ao encontro do conceito adotado pela UNCTAD (2010), sobre a dinamização da economia criativa.

Em Florianópolis há a presença de empreendedores criativos atuantes na gastronomia local, o que vai ao encontro do que Costa (2006) afirma para o dinamismo do sistema econômico que depende do surgimento do empreendedor como criador de novas combinações.

De acordo com a Classificação Nacional de Atividades Econômicas (IBGE, 2018), a cadeia produtiva da gastronomia possui uma variedade de atividades que podem se conectar ao sistema produtivo. Ao analisar a cadeia produtiva da gastronomia criativa de Florianópolis, foi possivel destacar que a relação e 
influência desta cadeia com a cadeia do turismo desperta um potencial desenvolvimento econômico da cadeia produtiva do turismo criativo, conforme foi percebido nos serviços turísticos oferecidos baseados na criatividade e cultura local.

A Conta Satélite da Cultura apresentada pela UNCTAD (2010) não foi identificada na região estudada. Florianópolis pode investir nas políticas públicas para promover estudos da conta satélite da cultura local com finalidade de mapear a dimensão da economia cultural local e promover ações direcionadas às demandas locais, principalmente na gastronomia, pois a cidade é reconhecida pela UNESCO como cidade criativa e, por esse fato, deve promover o desenvolvimento criativo da atividade.

\section{REFERÊNCIAS}

ALBERNAZ, P. ; BORGES, P. ; PASSOS, R. (2017). A dimensão econômica e os museus: uma síntese do caso brasileiro. In: VALIATI, L.; FIALHO, A. L. N. (org.). (2017). Atlas econômico da cultura brasileira: metodologia I. UFRGS / CEGOV. Porto Alegre.

BARDIN, L. (2002). Análise de Conteúdo. Lisboa, Portugal: Edições 70, LDA.

COSTA, A. B. (2006). 0 desenvolvimento econômico na visão de Joseph Schumpeter. Caderno IHU Ideias. UNISINOS. São Leopoldo, RS. Ano 4, n. 47.

DE PAULA, T. M. (2016). A economia criativa analisada na produção do souvenir gastronômico: um estudo sob o viés cultural. Dissertação de mestrado. Programa de Pós-Graduação em Turismo e Hospitalidade. Universidade de Caxias do Sul. Caxias do Sul, RS.

EPAGRI - Empresa de Pesquisa Agropecuária e Extensão Rural de Santa Catarina (2015). Plano Estratégico para o Desenvolvimento Sustentável da Maricultura Catarinense (2015-2020). Documento sob encomenda da Federação das Empresas de Aquicultura de Santa Catarina - FEAq.

FLORIPA CREATIVE CITY. (2017). City of gastronomy designated UNESCO creative city in 2014. Disponivel em: www.floripacreativecity.com Acesso em 13 out. 2017.

FLORIPAMANHÃ. (2017). Associação. Ações, programas e projetos em andamento. Disponível em: www. floripamanha.org Acesso em 24 nov. 2017.

FLORIPAMANHÃ. (2015). Projeto Saberes e Sabores/SC. Nucleo de Inovação Cultural - Labdesign CEART/UDESC. Associação Floriapamanhã. 
FLORIPAMANHÃ. (2008). Floripa 2030: agenda estratégica de desenvolvimento sustentável de Florianópolis na região. Disponivel em: www.floripamanhã.org Acesso em 11 jun. 2016.

HANSEN, P. B. (2004). Um modelo meso-analítico de medição de desempenho competitivo de cadeias produtivas. Tese (doutorado). Programa de pós-graduação em engenharia de produção. Universidade Federal do Rio Grande do Sul - UFRGS.

IBGE - Instituto Brasileiro de Geografia e Estatística. (2018). Comissão Nacional de Classificação. Classificação Nacional de Atividades Econômicas - CNAE. Disponível em https://cnae.ibge.gov.br/?option=com_cnae\&view=estrutura\&ltemid=6160\&chave=\&tipo=cnae\&versao_classe=7.0.0\&versao_ subclasse=9.1.0. Acesso em 05 set. 2018.

ICES BRASIL - Iniciativa Cidades Emergentes e Sustentáveis. (2015). Plano de Ação: Florianópolis sustentável. Disponível em: http://www.ibam.org.br/media/arquivos/estudos/plano_de_acao_florianopolis_sustentavel_bid_caixa.pdf Acesso em 24 out 2017.

IPHAN/SC - Instituto do Patrimônio Histórico e Artístico Nacional/SC. (2015). As Freguesias Luso-Brasileiras na Região da Grande Florianópolis. IPHAN/SC.

LANDRY, C.; HYAMS, J. (2012). The creative city index: measuring the pulse of the city. Comedia. United Kingdon.

LEITÃO, C. (2018). Floripa mais criativa: especialista explica a importância do fomento à Economia Criativa. Entrevista concedida à Laura Coutinho em 27/08/2018. Disponível em: https://ndonline.com.br/florianopolis/coluna/laura-coutinho/entrevista-especialista-explica-a-importancia-do-fomento-a-economia-criativa Acesso em 28 ago. 2018.

MARTINS, U. M. O.; GURGEL, L. I.; MARTINS, J. C. O. (2016). Experiências com a gastronomia local: um estudo de caso sobre movimento Slow Food e o turismo gastronômico na cidade de Recife - Brasil. PASOS. Revista de Turismo y Patrimonio Cultural. Vol. 14 N. 1. Pág. 229-241.

MELLO, L. G. (2015). Antropologia cultural: iniciação, teoria e temas. 20 ed. Petrópolis, Vozes.

MONDO, T. S.; BORGES, W. J. (2014). 0 desenvolvimento territorial sustentável no Ribeirão da Ilha: panorama histórico e perspectivas. DELOS - Revista Desarrollo Local Sostenible. Grupo eumed.net / Universidad de Málaga y Red Académica Iberoamericana Local-Global. Vol 7. N 18 - Febrero.

MTUR - Ministério do Turismo. (2017). Mapa do turismo brasileiro 2017. Disponível em: http://www. regionalizacao.turismo.gov.br. Acesso em 29 out. 2018. 
PIRES, A.; QUEIROZ, F.; RODRIGUES, W. S. (resp. ) (2013). Florianópolis: cidade UNESCO da gastronomia. Dôssie - Resumo executivo. Disponível em: http://floripamanha.org/wp-content/uploads/2014/02/unesco_relatorio_6a_2013.pdf. Acesso em jun 2016.

PORTER, M. E.; KRAMER, M. R. (2011). Creating Shared Value. Harvard Business Review; Jan/Feb., Vol. 89. Issue $1 / 2$, p. 62-77.

PREFEITURA DE FLORIANÓPOLIS. (2018). A cidade. Disponível em: http://www.pmf.sc.gov.br/entidades/ turismo/index.php?cms=a+cidade\&menu=5 Acesso em 12 abril 2018.

REIS, A. C. F. (Org.). (2008). Economia criativa como estratégia de desenvolvimento: uma visão dos países em desenvolvimento. São Paulo: Itaú Cultural.

RICHARDS, G. (2017). El consumo de turismo en la posmodernidad o en la modernidad líquida. Oikonomics - Revista de economía, empresa y sociedad. Universitat Oberta de Catalunya. N. 7. Mayo.

RICHARDS, G. (2015). Recipes for sustainable creative tourism. In: 3rd Business Management International Conference (BMIC). November 5-6, Thailand.

RICHARDS, G. (2010). Tourism development trajectories: from culture to creativity? Encontros científicos - tourism \& management studies, nr. 6. Escola Superior de Gestão, Hotelaria e Turismo, Universidade do Algarve.

RICHARDS, G. (2010). Trends and challenges in creative tourism. Internacional Conference on creative tourism. Barcelona, Espanha, 9-10 dez.

SEABRA, A. L. C. (2017). A "nova" comida de rua sob a ótica da economia criativa: uma análise dos food trucks na cidade de Natal \RN. Dissertação de mestrado. Programa de Pós-Graduação em Estudos Urbanos e Regionais da Universidade Federal do Rio Grande do Norte - UFRN. Natal.

SILVA, A. C. N. (2012). 0 papel da maricultura na configuração urbana do Ribeirão da llha. Dissertação de mestrado. Programa de Pós-Graduação em Urbanismo. História e Arquitetura da Cidade. Universidade Federal de Santa Catarina - UFSC, Florianópolis.

UNCTAD - Conferência das Nações Unidas sobre Comércio e Desenvolvimento. (2010). Creative economy report. Creative economy: a feasible development option. Disponivel em http://unctad.org/en/Docs/ ditctab20103_en.pdf. Acesso em 07 mar 2017.

UNESCO - United Nations Educational, Scientific and Cultural Organization. (2015). Creative cities network. Disponivel em: http://en.unesco.org/creative-cities/home. Acesso em 10 mai. 2016. 